\title{
Analisis Faktor - Faktor yang Mempengaruhi Pengembangan Subsektor Perikanan Tangkap di Pesisir Selatan Kabupaten Tulungagung dengan Konsep Pengembangan Ekonomi Lokal
}

\author{
Marindi Briska Yusni dan Eko Budi Santoso \\ Departemen Perencanaan Wilayah dan Kota, Fakultas Teknik Sipil dan Perencanaan, Institut \\ Teknologi Sepuluh Nopember (ITS) \\ e-mail: eko-budi@urplan.its.ac.id
}

\begin{abstract}
Abstrak-Kabupaten Tulungagung merupakan salah satu kabupaten di Jawa Timur yang memiliki potensi sumberdaya lokal perikanan tangkap di wilayah pesisirnya dan memiliki peran untuk pengembangan wilayah khususnya dalam pembangunan ekonomi. Produksi perikanan tangkap yang dihasilkan oleh Kabupaten Tulungagung tergolong besar, yaitu sebesar 206.408,952 ton. Namun potensi perikanan yang besar masih belum dimanfaatkan keseluruhan oleh masyarakat dimana diketahui terdapat masyarakat yang tergolong miskin di pesisir selatan Kabupaten Tulungagung sebesar 8,60\% atau 87.360 jiwa. Selain itu, jumlah keseluruhan perikanan tangkap yang mengalami proses pengolahan hanya $1.462,456$ ton atau hanya sekitar $0,7 \%$ dari total keseluruhan. Untuk itu diperlukan pengembangan subsektor perikanan tangkap dengan mengoptimalkan potensi lokal melalui pendekatan pengembangan ekonomi lokal. Penelitian ini bertujuan untuk mengetahui faktor - faktor apa saja yang berpengaruh untuk pengembangan subsektor perikanan tangkap di pesisir selatan Kabupaten Tulungagung dengan pendekatan PEL. Metode analisis yang digunakan untuk penelitian ini adalah confirmatory factor analysis.
\end{abstract}

Kata Kunci-pengembangan ekonomi lokal, perikanan tangkap.

\section{PENDAHULUAN}

$\mathrm{P}$ ENGEMBANGAN ekonomi lokal (PEL) merupakan proses dimana pemerintah lokal dan organisasi masyarakat terlibat untuk mendorong, merangsang, memelihara aktivitas usaha untuk menciptakan lapangan pekerjaan dengan proses dimana para pelaku pembangunan bekerja kolektif dengan mitra dari sektor publik, swasta dan non pemerintah untuk menciptakan kondisi lebih baik bagi pertumbuhan ekonomi dan kesempatan kerja. PEL ditekankan pada tercapainya pertumbuhan ekonomi melalui penciptaan nilai tambah, penciptaan kesempatan kerja baru, pemerataan pendapatan di antara masyarakat terutama masyarakat miskin, dan meningkatkan daya saing daerah, dimana semuanya bermuara pada sasaran utama jangka panjang PEL yaitu pengurangan kemiskinan secara signifikan dan peningkatan kesejahteraan kehidupan masyarakat lokal. [1][2]

Wilayah pesisir memiliki potensi cukup besar dalam pembangunan wilayah karena memiliki sumberdaya alam yang kaya dan beragam serta memiliki aksesibilitas yang sangat baik untuk berbagai kegiatan ekonomi seperti transportasi, pelabuhan, industri, permukiman dan pariwisata. Oleh karena itu pada kawasan pesisir, sumber daya perikanan merupakan potensi unggulan yang menjadi gantungan hidup masyarakatnya. [3]

Perikanan merupakan semua kegiatan yang berhubungan dengan pengelolaan dan pemanfaatan sumber daya ikan dan lingkungannya mulai dari pra-produksi, produksi, pengolahan sampai dengan pemasaran dilaksanakan dalam suatu sistem bisnis perikanan. Oleh karena adanya pembangunan subsektor perikanan diharapkan mampu meningkatkan produksi, memperluas kesempatan kerja dan kesempatan berusaha, serta dapat memberikan kontribusi dalam peningkatan kesejahteraan nelayan dan meningkatkan perekonomian daerah. Satu daerah yang potensial untuk dilakukannya pembangunan dalam subsektor perikanan adalah Pesisir Selatan Kabupaten Tulungagung. [4]

Kabupaten Tulungagung merupakan salah satu kabupaten di Jawa Timur yang memiliki potensi sumberdaya lokal perikanan tangkap di wilayah pesisirnya yang memiliki peran untuk pengembangan wilayah khususnya dalam pembangunan ekonomi. Tercatat pada data PDRB Kabupaten Tulungagung bahwa subsektor perikanan memiliki kontribusi terhadap perkembangan ekonomi Kabupaten Tulungagung. Pada tahun 2015, subsektor perikanan menyumbang sebesar 911.718,83 juta rupiah atau $15,05 \%$. Angka tersebut merupakan sumbangan subsektor perikanan terhadap PDRB kabupaten tebesar selama kurun waktu 5 tahun (PDRB Kabupaten Tulungagung Tahun 2015). Selain itu pada RTRW Kabupaten Tulungagung, wilayah Tulungagung direncanakan menjadi kawasan perikanan dan minapolitan dengan pengembangan perikanan tangkap dilakukan di empat kecamatan yaitu Kecamatan Pucanglaban, Kecamatan Kalidawir, Kecamatan Tanggunggunung, dan Kecamatan Besuki. [5][6]

Jumlah Produksi perikanan tangkap yang dihasilkan oleh Kabupaten Tulungagung tergolong besar, yaitu sebesar $206.408,952$ ton. Namun, jumlah perikanan yang dilakukan pengolahan masih sedikit yaitu hanya $1.462,456$ ton dari total 206.408,925 atau hanya sekitar 0,7\% (Dinas Kelautan dan 
Perikanan Kabupaten Tulungagung, 2016). Kemudian, dari total seluruh masyarakat nelayan yang ada di pesisir selatan Kabupaten Tulungagung, masyarakat yang bekerja sebagai nelayan adalah 12.785 jiwa dari total keseluruhan masyarakat di empat kecamatan yaitu 52.135 jiwa. Hal ini menunjukkan bahwa terdapat tenaga kerja lokal, namun belum banyak dari mereka yang bekerja di subsektor perikanan tangkap dalam hal subsektor perikanan tangkap, serta prosentase masyarakat miskin di pesisir Selatan Kabupaten Tulungagung sebesar $8,60 \%$ atau sebesar 87.360 jiwa masyarakat pesisir masih tergolong masyarakat miskin, padahal pesisir Selatan Tulungagung memiliki sumber daya lokal perikanan tangkap yang besar. [7][8]

Dijelaskan pula didalam RPJMD Kabupaten Tulungagung Tahun 2014-2018 bahwa potensi perikanan di Kabupaten Tulungagung sangatlah prospektif untuk pengembangan di masa yang akan datang karena merupakan sumber pertumbuhan ekonomi bagi masyarakat sehingga mampu meningkatkan kesejahteraan masyarakat. Kesejahteraan masyarakat dapat ditingkatkan dengan cara adanya kesempatan kerja bagi masyarakat lokal. [6]

Berdasarkan kondisi eksisting diatas, pemanfaat sumberdaya lokal subsektor perikanan tangkap di pesisir selatan Kabupaten Tulungagung belum optimal. Oleh karena untuk pengembangan subsektor perikanan tangkapnya, perlu diketahui faktor - faktor apa saja yang mempengaruhi pengembangan subsektor perikanan tangkap di pesisir selatan Kabupaten Tulungagug.

\section{METODE PENELITIAN}

\section{A. Metode Pengumpulan Data}

Dalam penelitian ini, pengumpulan data dilakukan dengan survei primer dan survei instansional. Survei primer dilakukan dengan cara mengamati langsung keadaan di lapangan dan melakukan wawancara. Sedangkan untuk survei instansional yaitu survei ke beberapa instansi pemerintah untuk mendapatkan data - data yang mendukung penelitian. Adapun instansi pemerintahan yang dituju untuk penelitian ini adalah BAPPEDA, Dinas Kelautan dan Perikanan, Dinas PU Bina Marga dan Cipta Karya, Kantor Kecamatan, dan instansi lainnya.

\section{B. Metode Analisis Data}

Dalam menganalisis faktor - faktor yang mempengaruhi pengembangan subsektor perikanan tangkap di pesisir selatan Kabupaten Tulungagung dengan konsep PEL digunakan analisis faktor konfirmatori atau confirmatory factor analysis, dengan menganalisis variabel - variabel konsep PEL dan Perikanan Tangkap yang didapatkan dari hasil kajian pustaka. Variabel - variabel tersebut yang sudah dikelompokkan tiap faktornya kemudian dilakukan skoring menggunakan Skala Likert dalam bentuk kuesioner tingkat kepentingan dan dibagikan kepada responden di wilayah penelitian. Penentuan jumlah responden menggunakan Simple Random Sampling. Simple Random Sampling merupakan teknik pengambilan sampel yang dilakukan secara acak tanpa memperhatikan strata yang ada dalam populasi tersebut. Responden diambil dari sampel di desa - desa pesisir selatan Kabupaten Tulungagung dan didapatkan total 99 sampel menggunakan rumus slovin untuk dijadikan responden. Adapun responden merupakan masyarakat yang bekerja di bidang perikanan tangkap.

Kemudian, hasil skoring ditiap - tiap kuesioner diolah dengan menggunakan analisis faktor konfirmatori atau confirmatory factor analysis, dimana tujuan dari Confirmatory factor analysis adalah untuk mengkonfirmasikan atau menguji model yang perumusannya berasal dari teori.

\section{HASIL DAN DISKUSI}

Kabupaten Tulungagung terletak pada posisi $111^{\circ} 43^{\prime}$ sampai dengan $112^{\circ} 07^{\prime}$ bujur timur dan $7^{\circ} 51^{\prime}$ sampai $8^{\circ} 18^{\prime}$ lintang selatan. Secara keseluruhan, Kabupaten Tulungagung memiliki luas mencapai $1.000,65 \mathrm{~km}^{2}$ dan terdapat 19 kecamatan serta 271 desa/keluran. Untuk Lingkup wilayah penelitian yang digunakan yaitu pesisir selatan Kabupaten Tulungagung terdiri dari 4 (empat) kecamatan dengan fokus pada 9 (sembilan) desa dengan wilayah pesebaran yaitu: Kecamatan Besuki terdiri dari desa Keboireng, desa Besuki, dan desa Besole. Kecamatan Kalidawir terdiri dari desa Kalibatur dan desa Rejosari. Kecamatan Tanggunggunung terdiri dari desa Ngrejo dan desa Jengglungharjo. Kecamatan Pucanglaban terdiri dari desa Panggungkalak dan desa Pucanglaban.

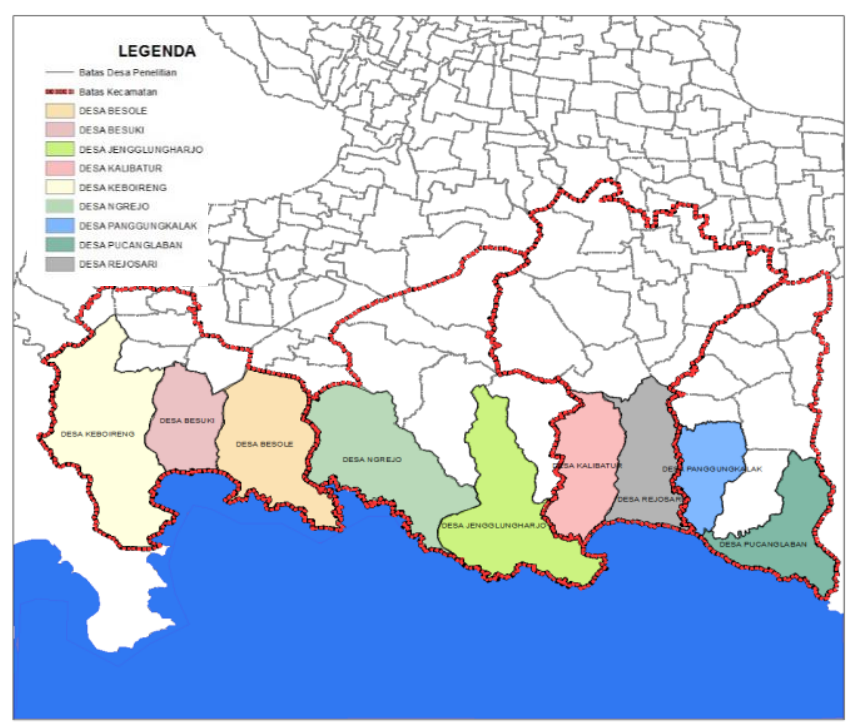

Gambar 1. Peta Lingkup Wilayah Penelitian.

C. Penentuan faktor - faktor yang berpengaruh terhadap pengembangan subsektor perikanan tangkap di pesisir selatan Kabupaten Tulungagung

Analisis faktor - faktor yang berpengaruh terhadap pengembangan subsektor perikanan tangkap di pesisir selatan Kabupaten Tulungagung dilakukan dengan menggunakan kuisioner skala likert yang dibagikan kepada responden dan hasil dari skoring likert dilakukan uji confirmatory factor analysis (CFA) untuk mengetahui faktor - faktor apa saja yang mempengaruhi pengembangan subsektor perikanan tangkap. Uji CFA dalam penelitian dilakukan untuk mengkonfirmasi pengaruh dari variabel - variabel suatu faktor dengan 
mengunakan SPSS, jika dinyatakan valid maka faktor tersebut pengembangan subsektor perikanan tangkap sebagai berikut. berpengaruh, namun jika tidak valid maka harus direduks Variabel dalam faktor dinyatakan valid apabila:

- memiliki nilai $\mathrm{KMO} \geq 0,5$

- memiliki nilai Sig. $<0,05$

- memiliki nilai MSA $\geq 0,5$

Kemudian dilakukan uji CFA dan didapatkan hasil yar ditunjukkan pada tabel berikut:

Tabel 1.

Hasil Uji CFA Faktor - Faktor Yang Mempengaruhi Pengembangan Subsektor Perikanan Tangkap Di Pesisir Selatan Kabupaten Tulungagung

\begin{tabular}{|c|c|c|c|c|}
\hline FAKTOR & Variabel & KMO & Sig. & MSA \\
\hline Klaster & $\begin{array}{l}\text { Peran } \\
\text { masyarakat } \\
\text { Peran } \\
\text { pemerintah } \\
\text { Peran swasta } \\
\text { Kerjasama } \\
\text { stakeholder }\end{array}$ & 0,685 & 0,000 & $\begin{array}{l}0,622 \\
0,651 \\
0,885\end{array}$ \\
\hline $\begin{array}{l}\text { Manfaat } \\
\text { ekonomi }\end{array}$ & $\begin{array}{l}\text { Pendapatan } \\
\text { masyarakat } \\
\text { Kesempatan } \\
\text { kerja }\end{array}$ & 0,500 & 0,000 & $\begin{array}{l}0,500 \\
0,500\end{array}$ \\
\hline SDM & $\begin{array}{l}\text { Tenaga kerja } \\
\text { Kualitas tenaga } \\
\text { kerja }\end{array}$ & 0,500 & 0,019 & $\begin{array}{l}0,500 \\
0,500\end{array}$ \\
\hline $\begin{array}{l}\text { Sumber Daya } \\
\text { Lokal }\end{array}$ & $\begin{array}{l}\text { Jenis bahan } \\
\text { baku } \\
\text { Ketersediaan } \\
\text { bahan baku } \\
\text { Perolehan } \\
\text { bahan baku }\end{array}$ & 0,510 & 0,000 & $\begin{array}{l}0,506 \\
0,506 \\
0,607\end{array}$ \\
\hline Pemasaran & $\begin{array}{l}\text { Strategi } \\
\text { pemasaran } \\
\text { Permintaan } \\
\text { pasar }\end{array}$ & 0,510 & 0,000 & $\begin{array}{l}0,500 \\
0,500\end{array}$ \\
\hline $\begin{array}{l}\text { Teknologi } \\
\text { perikanan }\end{array}$ & $\begin{array}{l}\text { Alat tangkap } \\
\text { perikanan } \\
\text { Teknologi } \\
\text { pengolahan } \\
\text { perikanan }\end{array}$ & 0,500 & 0,000 & $\begin{array}{l}0,500 \\
0,500\end{array}$ \\
\hline $\begin{array}{l}\text { Proses } \\
\text { Produksi }\end{array}$ & $\begin{array}{l}\text { Jumlah } \\
\text { produksi } \\
\text { Hasil produksi } \\
\text { Biaya produksi }\end{array}$ & 0,525 & 0,019 & $\begin{array}{l}0,639 \\
0,517 \\
0,518\end{array}$ \\
\hline Modal & $\begin{array}{l}\text { Ketersediaan } \\
\text { modal } \\
\text { Sumber modal }\end{array}$ & 0,500 & 0,000 & $\begin{array}{l}0,500 \\
0,500\end{array}$ \\
\hline $\begin{array}{l}\text { Sarana dan } \\
\text { prasarana }\end{array}$ & $\begin{array}{l}\text { TPI dan PPI } \\
\text { Aksesibilitas } \\
\text { Listrik } \\
\text { Air bersih }\end{array}$ & 0,555 & 0,000 & $\begin{array}{l}0,521 \\
0,629 \\
0,560 \\
0,539\end{array}$ \\
\hline Pengolahan & $\begin{array}{l}\text { Lokasi } \\
\text { pengolahan } \\
\text { Proses } \\
\text { pengolahan }\end{array}$ & 0,500 & 0,024 & 0,500 \\
\hline
\end{tabular}

Sumber: Hasil Analisis, 2017

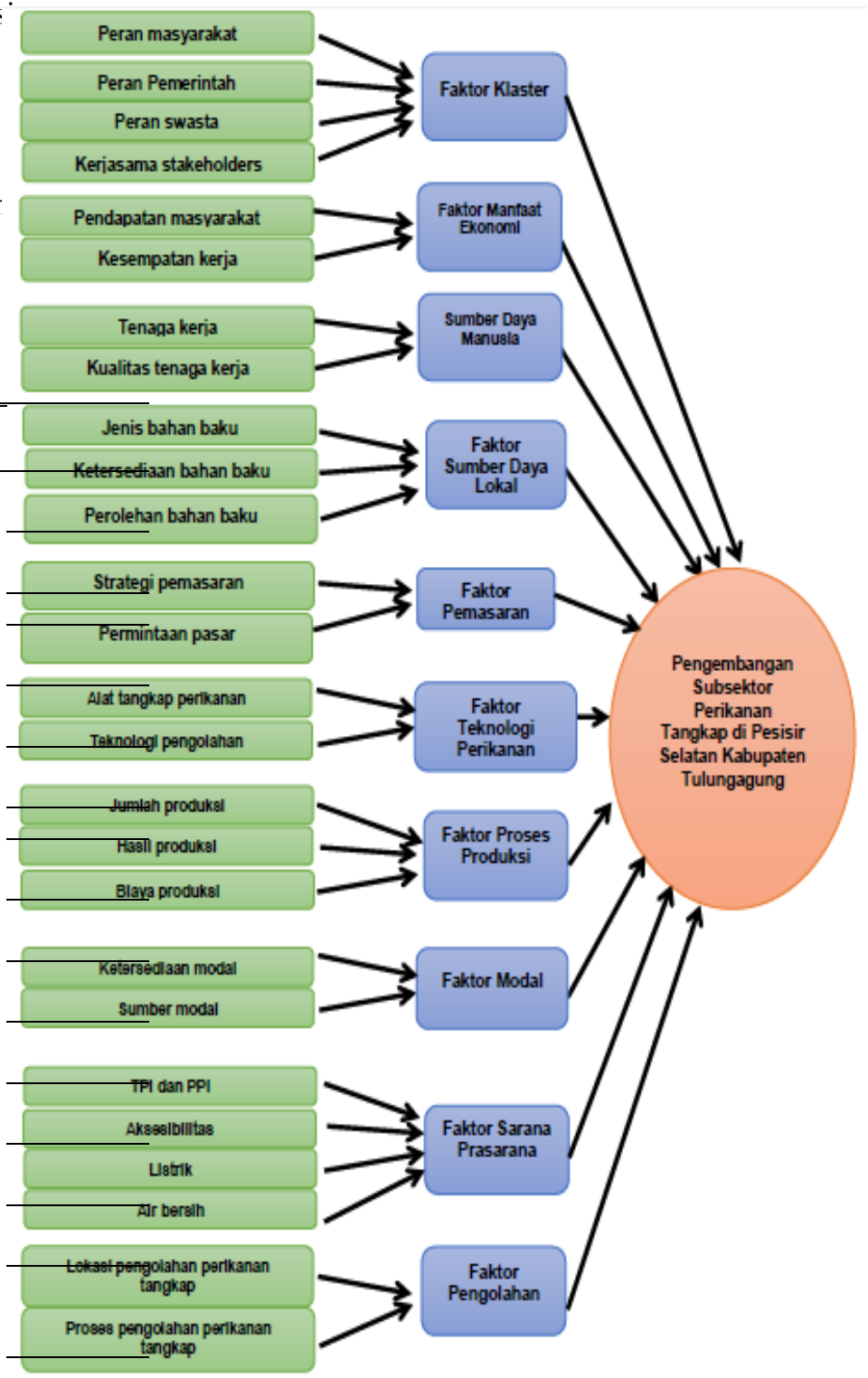

Gambar 2. Diagram Faktor - Faktor Pengembangan Subsektor Perikanan Tangkap di Pesisir Selatan Kabupaten Tulungagung

Selanjutnya, dilakukan pembahasan untuk faktor - faktor yang mempengaruhi pengembangan subsektor perikanan tangkap di pesisir selatan Tulungaung adalah sebagai berikut:

1). Faktor Klaster

Faktor klaster terdiri dari peran masyarakat, peran pemerintah, dan peran swasta. Untuk peran masyarakat ditunjukkan dengan adanya KUB (Kelompok Usaha Bersama) di bidang penangkapan ikan dan pengolahan ikan. KUB Penangkapan Ikan antara lain KUB Mina Klatak, Rayap Pereng, NArimo Mino, Green Fish, Anmis Raya, Media Mina II. KUB Pengolahan ikan antara lain KUB Mina Melati, Mina Usaha, Mina Asri, dan Mina Agung. Untuk peran pemerintah adalah melalui pembinaan pelatihan dan bantuan usaha untuk mendukung pengembangan subsektor perikanan tangkap. Sedangkan peran swasta masih belum ditemui di wilayah ini. variabel didalam faktor dinyatakan valid semua sehingga tidak ada yang tereduksi, oleh karena itu faktor - faktor yang berpenaruh untuk pengembangan subsektor perikanan tangkap di pesisir selatan Kabupaten Tulungagung di gambarkan didalam diagram faktor - faktor yang mempengaruhi

2). Faktor Manfaat Ekonomi 
Faktor manfaat ekonomi terdiri dari pendapatan masyarakat dan kesempatan kerja. Pendapatan masyarakat di perikanan tangkap tidak menentu karena perolehan ikan tergantung musim atau cuaca. Sedangkan untuk kesempatan kerja di bidang perikanan tangkap adalah masyarakat bekerja sebagai nelayan dan pengolah ikan.

3). Faktor Sumber Daya Manusia

Faktor sumber daya manusia terdiri dari tenaga kerja dan kualitas tenaga kerja. Untuk tenaga kerja yang bekerja sebagai nelayan setidaknya ada 1000 jiwa, sedangkan untuk yang bekerja di bidang pengolahan perikanan tangkap masih sedikit.

4). Faktor Sumber Daya Lokal

Sumber daya lokal terdiri dari jenis bahan baku, ketersediaan bahan baku, dan perolehan bahan baku. Untuk jenis bahan baku, setidaknya ada 36 jenis ikan setiap tahunya antara lain ikan kakap, sebelah, teri, tongkol, layur, dll. Jumlah ikan hasil tangkapan pada tahun 2016 sebesar 1.775.180 ton. Sedangkan untuk ketersedian bahan baku tergantung cuaca dan musim. Ketika musim hujan perolehan ikan tangkapan lebih sedikit dibandingkan dengan musim kemarau. Sementara untuk perolehan bahan baku sendiri didapatkan di pantai Klatak, pantai Sidem, Pantai Popoh, Pantai Sine, Pantai Dlodo, Pantai Brumbum, dan Pantai Sanggar.
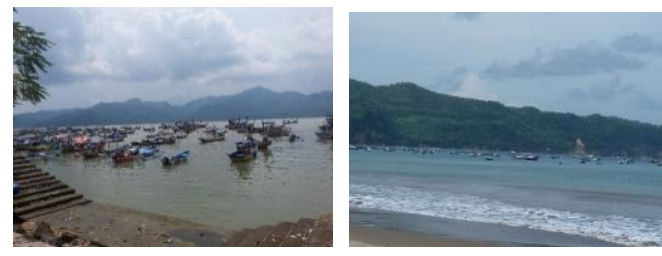

Gambar 3. pantai popoh (kiri) dan pantai sine (kanan).

Sumber: survey primer, 2017.

\section{5). Faktor Pemasaran}

Faktor pemasaran terdiri dari strategi pemasaran dan permintaan pasar. Untuk strategi pemasaran, ikan hasil tangkapan dan yang sudah diolah dijual di pasar-pasar desa dan kios - kios yang terletak di dekat pantai dengan tujuan konsumen yang membeli adalah para pengunjung pantai. Dari pemerintah sendiri pemasaran dilakukan dengan cara diikut sertakan dalam pameran UMKM.

6). Faktor Teknologi Perikanan

Faktor teknologi perikanan terdiri dari alat tangkap perikanan dan teknologi pengolahan. Untuk alat tangkapnya terdiri dari Purse Seine, Payang, Pancing, Gillnet, Jaring insang hanyut, Rawai tetap, Tonda, Pukat Pantai dan perangkap lainnya dengan jumlah unit keseluruhan pada tahun 2016 sebesar 403 unit. Sedangkan untuk merek kapal yang digunakan para nelayan adalah Dongfeng, Mitsubishi, Kubota, Honda, Fuso, Yamaha, Zusuki, Yanmar, dan tanpa mesin dengan jumlah total unit pada tahun 2016 sebesar 403 unit. Untuk teknologi pengolahan perikanan masih menggunakan teknologi sederhana untuk pengolahannnya yang terdiri dari pengasapan, pengeringan, pemindangan, dan pembuatan bakso ikan.

7). Faktor Proses Produksi
Faktor proses produksi terdiri dari jumlah produksi, hasil produksi, dan biaya produksi.

Tabel 2.

Jumlah dan hasil produksi produk perikanan tangkap

\begin{tabular}{|c|c|}
\hline Jenis Produksi Pengolahan & $\begin{array}{c}\text { Hasil Produksi } \\
\text { Pengolahan } \\
(2016) \text { ton }\end{array}$ \\
\hline Pengeringan & 198,88 \\
\hline Pemindangan & $2.155,65$ \\
\hline Pemanggangan & $7.567,92$ \\
\hline Terasi & 4,04 \\
\hline Kerupuk & 1,25 \\
\hline Olahan Lainnya & $1.433,54$ \\
\hline TOTAL & $11.361,27$ \\
\hline
\end{tabular}

Sumber: profil perikanan kabupaten Tulungagung, 2016

Sedangkan untuk biaya produksi masih tergolong mahal karena lokasi yang jauh dari pusat kota.

8). Faktor Modal

Faktor modal terdiri dari ketersediaan moda dan sumber modal. Bantuan berupa uang atau dana pinjaman juga sudah tersedia di Bank UMKM Kabupaten Tulungagung dan beberapa koperasi yang terletak di desa - desa. Untuk para pengusaha perikanan dan pengolah perikanan yang membutuhkan bantuan modal atau dana, pihak Dinas Perikanan siap membantu sebagai perantara dari masyarakat ke lembaga keuangan dengan cara memberikan surat keterangan usahaa dan surat pengantar pengajuan dana pinjaman. Sumber modal untuk perikanan tangkap di pesisir selatan kabupaten Tulungagung diperoleh dari berbagai sumber seperti bank yang terdiri dari bank Jatim dan bank Syariah. Kemudian untuk pemerintah Kabupaten Tulungagung sendiri juga menyediakan bank UMKM. Bank UMKM merupakan kelompok bank - bank yang bekerjasama sama dengan pemerintah daerah untuk memberikan pinjaman dana dan modal kepada para pengusaha. Bank UMKM terdiri dari BRI, BNI, Bank Jatim.

9). Faktor Sarana Prasarana

Faktor sarana prasarana terdiri dari TPI PPI, Aksesibilitas, Listrik, dan Air bersih. Untuk TPI dan PPI) yang ada dalam rangka untuk mendukung pengembangan perikanan tangkap yang ada di di Pesisir Selatan Kabupaten Tulungagung yaitu:

a). Tempat Pelelangan Ikan (TPI) Popoh yang terletak di Desa Besole

b). Tempat Pelelangan Ikan (TPI) Sine yang terletak di Desa Kalibatur

c). Tempat Pelelangan Ikan (TPI) Brumbun yang terletak di Desa Ngrejo

d). Tempat Pelelangan Ikan (TPI) Klatak yang terletak di Desa Keboireng

Untuk aksesibilitas, tidak semua kecamatan dan desa di wilayah penelitian dijangkau oleh transportasi umum. Adapun untuk desa Panggungkalak dan Pucanglaban masih belum dilalui oleh kendaraan umum karena akses menuju lokasi yang sulit. Sementara itu, untuk listrik dan air bersih sudah menjangkau semua desa.

10). Faktor Pengolahan

Faktor pengolahan terdiri dari lokasi pengolahan perikanan tangkap dan proses pengolahan perikanan tangkap. Lokasi 
pengolahan perikanan tangkap di pesisir selatan Kabupaten Tulungagung terdapat di desa Besuki, desa Besole, Desa Kalibatur, Desa Keboireng, Desa Jengglungharjo, dan desa Rejosari. Di setiap desa tersebut, lokasi pengolahan perikanan tangkap terpusat di dekat pantai. Dimana masyarakat yang bekerja di bidang ini mengolah dan menjualnya langsung.

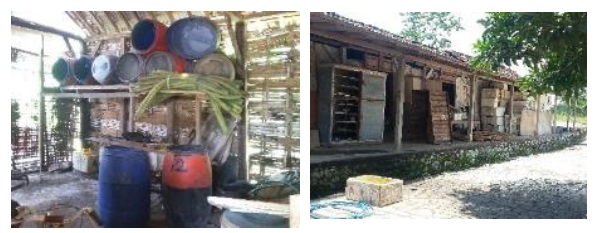

Gambar 4. Lokasi pengolahan ikan di desa Besuki Sumber: Survey primer, 2017

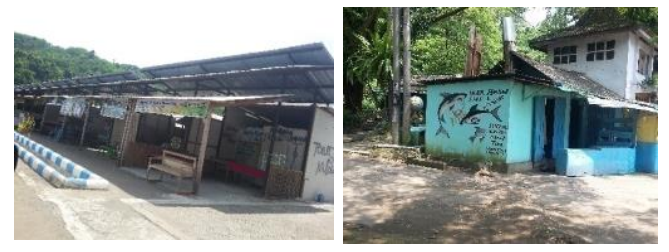

Gambar 5. Lokasi pengolahan ikan di Sine Desa Kalibatur (kiri) dan pengolahan ikan Popoh desa Besole (kanan).

Sumber: survey primer, 2017.

Sementara itu, untuk proses pengolahan perikanan tangkap masih sederhana, dimana para pengolah masih menggunakan alat tradisional seperti pemanggangan tradisional yang menggunakan kipas manual, pengeringan yang dijemur, pengasinan yang prosesnya dilakukan manual, serta pembuatan produk-produk olahan seperti fillet, kerupuk, dan terasi. Kalaupun menggunakan alat, alat yang digunakan adalah berupa mixer dan blender.

\section{KESIMPULAN}

Berdasarkan analisis dan pembahasan yang telah dilakukan sebelumnya, dapat disimpulkan bahwa untuk melakukan pengembangan subsektor perikanan tangkap di pesisir selatan Kabupaten Tulungagung dengan menggunakan konsep PEL perlu memperhatikan 10 (sepuluh) faktor, antara lain: faktor klaster, faktor manfaat ekonomi, faktor sumber daya manusia, faktor sumber daya lokal, faktor pemasaran, faktor teknologi perikanan, faktor proses produksi, faktor modal, faktor sarana prasarana, dan faktor pengolahan. Adapun beberapa faktor yang masih memiliki permasalahan pengembangan perikanan tangkap antara lain faktor klaster, faktor pemasaran, faktor pengolahan, dan faktor sumber daya manusia.

\section{DAFTAR PUSTAKA}

[1] N. G. Blakely, E. J., \& Leigh, Planning Local Economic Development Theory and Practice. United State of America: SAGE Publications, Inc, 2010.

[2] H. Rahma, Acuan Penerapan Pengembangan Ekonomi Lokal untuk Kota dan Kabupaten. Jakarta: Direktorat Jenderal Cipta Karya, Kementerian Pekerjaan Umum, 2012.

[3] R. Dahuri, Konservasi Sumberdaya Alam Laut dan Ekosistemnya. Dirjen Pesisir dan Pulau-Pulau Kecil. Jakarta: Departemen Kelautan dan Perikanan, 2000.

[4] A. Trisnawati, "Peranan Sub Sektor Perikanan dalam Pembangunan Wilayah Kabupaten Tanjung Gunung, Provinsi Jambi," Institut Pertanian Bogor, 1999.

[5] Rencana Tata Ruang Wilayah Kabupaten Tulungagung 20112031. Tulungagung, 2011.

[6] Rencana Pembangunan Jangka Menengah Daerah (RPJMD) Kabupaten Tulungagung 2014-2018. Tulungagung, 2014.

[7] Potensi Kelautan dan Perikanan di Kabupaten Tulungagung. Tulungagung: Dinas Perikanan dan Kelautan Kabupaten Tulungagung, 2016.

[8] "Peranan Sub Sektor Perikanan dalam Pembangunan Wilayah Kabupaten Tanjung." [Online]. Available: http://dkp.tulungagung.go.id/index.php/potensi. 